\title{
Use of Imaging Techniques as a Support for the Preventive Conservation Strategy of Wall Paintings: Application to the Medieval Decors of the Château de Germolles
}

\author{
Christian Degrigny ${ }^{1,3(\triangle)}$ (D), Frank Boochs ${ }^{2}$, Laura Raddatz ${ }^{2}$, \\ Jonas Veller ${ }^{2}$, Carina Justus ${ }^{2}$, and Matthieu Pinette ${ }^{3}$ \\ ${ }^{1}$ Haute Ecole Arc Conservation-restauration HES-SO University of Applied \\ Sciences and Arts Western Switzerland, Espace de l'Europe 11, \\ 2000 Neuchâtel, Switzerland \\ christian.degrigny@he-arc.ch \\ 2 Institute for Spatial Information and Surveying Technology, \\ University of Applied Sciences - i3Mainz, Lucy-Hillebrand-Straße 2, \\ 55128 Mainz, Germany \\ frank.boochs@geoinform.hs-mainz.de, \\ \{laura. raddatz, jonas.veller, carina.justus\}@hs-mainz.de \\ ${ }^{3}$ Château de Germolles, 100 place du 5 Septembre 1944, \\ 71640 Mellecey, France \\ matthieu.pinette@gmail.com
}

\begin{abstract}
Imaging techniques were used to document and monitor physical damage to the unique wall paintings at the Château de Germolles, Burgundy, France. Photogrammetry combined with scanning are the most appropriate techniques to monitor the evolution of microcrack networks in the cornice overhanging the paintings and preserved as a witness to 19th century additions.

However, the application of these techniques was challenged due to the given constraints of a working height of $4 \mathrm{~m}$ and the required accuracy of a tenth of a millimetre. A special effort was therefore necessary to ensure sufficient stability of the acquisition protocol and to make it relevant during the four measurement campaigns planned over the two years of the project.

The analysis of photogrammetric data has made it possible to document certain macro-deformations of the cornice according to the seasons of the year. The microcracks could be visualized and monitored from transformed 3D models of each segment for the different campaigns. The results obtained show only local movements, mainly on the walls that are most exposed to the specific climatic conditions of each season.
\end{abstract}

Keywords: Medieval decorations - Physical damage - Imaging techniques · Photogrammetry $\cdot$ Scanning $\cdot$ Monitoring $\cdot$ Preventive conservation 


\section{Introduction}

The château de Germolles, the only princely residence of the Dukes of Burgundy Valois to be so well preserved, has been benefiting for about ten years from a major campaign to document its 14 th century mural paintings [1].

This work has made it possible to specify the original character of the residual decorations, to study the nature of the constituent materials and the pictorial techniques used, to evaluate their conservation condition and to propose hypotheses for restitution to the public visiting the château.

Cracks are visible in the upper parts of the decorations, seeming to indicate certain physical damages. These have been confirmed by IR thermography: they appear to be detachments between the painted plaster and the walls.

The risk of detachment of the painted decorations and loss of this unique heritage associated with the negative impact on the tourist activities of the site has led the managers of the château to set up a campaign to monitor the damages observed. This preventive conservation approach is the subject of this article.

In the following, we describe the site and its painted decorations, the knowledge recently acquired about them, including the physical damages observed. We then present the imaging techniques used to understand the risks of evolution of these damages. Finally, we present some results which are then discussed in the general context of safeguarding this unique Burgundian heritage.

\section{Wall Paintings in the Château de Germolles: An Overview}

\subsection{Historical Background, Rediscovery and Restoration of the Paintings}

The Château de Germolles is located in Southern Burgundy, $10 \mathrm{~km}$ west of Chalonsur-Saône, France. Built in the second half of the 14th century, this residence is the only example of its type still well preserved in France. Philip the Bold, Duke of Burgundy and brother of King Charles V, acquired the estate of Germolles in 1380. The following year, he offered it to his wife, Margaret of Flanders. Important works are immediately undertaken; they will last 20 years. The aim was to transform the austere and archaic 13th century fortress into a country palace. To do this, the Duchess summoned the artists who were attached to the ducal couple: the architect Drouet de Dammartin, the sculptor Claus Sluter and the painter Jean de Beaumetz [2].

The main building is undoubtedly the most exceptional part of the place. It has retained its three-storey structure, where the first floor is the suite of the hold. This is where the paintings of Jean de Beaumetz and his workshop are located. Medieval account books provide information on the artists involved and the list of materials used. We learn that important metal decorations were used [3].

Part of the decorations were accidentally rediscovered in a room during World War II under the layer of plaster applied after the wall paintings had been keyed at the beginning of the 19th century. However, the clearing of the walls was not completed until the 1970s. White letters P and M, initials of the first names of the princes, repeated diagonally, and thistles, also white, appear between these letters. According to 


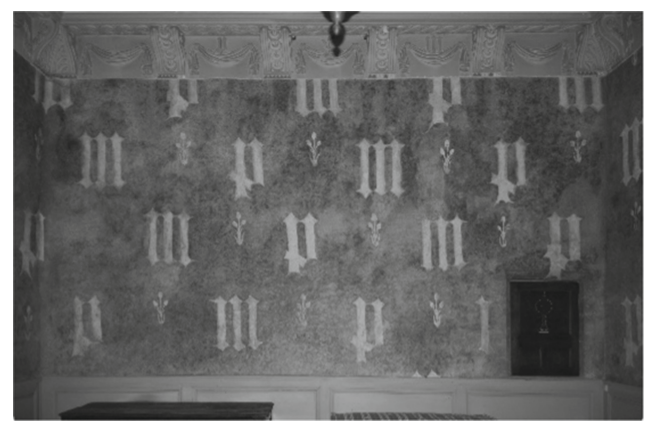

Fig. 1. Photograph of the west wall of Margaret of Bavaria's dressing-room in visible light, showing the initials of the Dukes of Burgundy separated by thistles, (C) Papiashvili.

medieval records, we were able to identify the room as the dressing-room of Margaret of Bavaria, daughter-in-law of Margaret of Flanders. The château was listed as historical monument in 1989 and a major restoration campaign carried out from 1989 to 1995 led to filling in the holes due to the keying process and re-homogenizing the decoration using the trattegio technique. Figure 1 shows the preserved decorations of the west wall of the room. The lower panelling, as well as the cornice and ceiling, still bear witness to the transformations undergone by the château following the French Revolution.

\subsection{Re-documentation of the Paintings}

Apart from a few rare analyses, the restoration work was not documented. Moreover, they do not reflect the extreme richness of the decorations, especially the presence of the metallic ornaments mentioned above.

The involvement of the main author of this article both in the activities of the château as co-manager and in those of the European COSCH action (Colour and Space in Cultural Heritage - www.cosch.info) as Swiss national delegate for the Haute Ecole Arc Conservation-restoration, Neuchâtel, led him to carry out some preliminary work on these paintings through short term scientific missions of the $\mathrm{COSCH}$ action. This work, which revealed the original character of these decorations and thus their interest, made it possible to make these wall paintings a case study of the $\mathrm{COSCH}$ Action. It then benefited from greater technical and scientific support from the action, as well as from the Regional Direction of Cultural Affairs (DRAC) Burgundy Franche-Comté, which provided additional funding.

The "Germolles" project took place over 4 years, from 2012 to 2016. Although other decorations had been discovered since then, it focused on the dressing-room of Margaret of Bavaria and made it possible to:

- Collect all existing historical records on the paintings and their restoration;

- Appreciate the extent of the original decoration and confirm the respectful character of the restoration intervention of 1989-1995; 
- Study with the most innovative and least possible invasive imaging and analytical techniques the constituent materials, in particular the residues of the metallic decorations found on the thistles;

- Specify the pictorial techniques used: the letters $\mathrm{M}$ and $\mathrm{P}$ were created with stencils and painted in reserve on the green background while the thistles, made of a green tin foil covered with fine gold leaf enhanced with paint, were glued on the latter. The letters $\mathrm{P}$ were also embellished with arabesques.

- Suggest the initial rendering using augmented reality (Fig. 2).

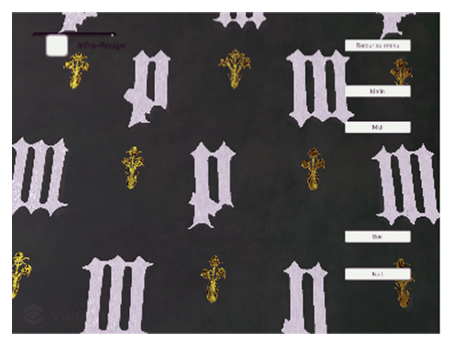

Fig. 2. Proposal for rendering the wall decoration of Margaret of Bavaria's dressing-room using augmented reality, (C) Germolles. (Colour figure online)

The information collected have been partly integrated into the guided tour and the public enjoying the augmented reality experience can better perceive the refinement of the interior decoration which, in the Middle Ages, was supposed to reflect the interest of the princes in the subtleties of the surrounding nature. Walking through the princely floor of the château, one wanders through green meadows dotted with symbolic floral decorations (the thistle is the symbol of fidelity and protection) separating the letters of the Dukes, including the P of Philip courteously embellished.

\subsection{Physical Damage to Be Documented}

The documentation work carried out on the paintings also revealed significant physical damage to their upper part under the 19th century cornice. Figure 3 shows the areas of detachment between the painted plaster and the west wall of the Margaret of Bavaria's dressing-room quantitatively documented through IR thermography. The same damage was observed on the other three walls, of which only the east wall is interior.

The 19th century cornice is also dotted with networks of cracks (Fig. 4a) resulting in other damage, including local detachment of the filling material used during the conservation intervention of 1989-1995 (Fig. 4b).

The mural decorations of the Château de Germolles are one of the highlights of the tour of the site. The physical detachment of the upper part of the painted plaster, induced or not by movements of the cornice, would not only be an irreversible damage but would also be detrimental to the appreciation of the painted decoration by the visitors. The site managers therefore wished to be reassured about the overall stability. 


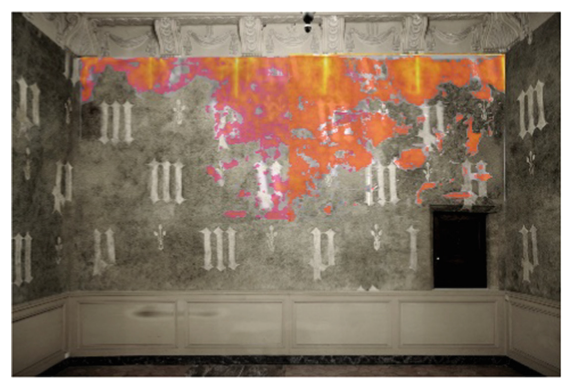

Fig. 3. Distribution of areas of detachment of the painted plaster detected by IR thermography on the west wall of Margaret of Bavaria's dressing-room, (C) Tedeschi \& Cucchi. (Colour figure online)

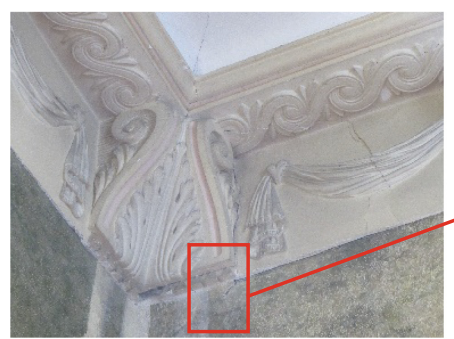

a

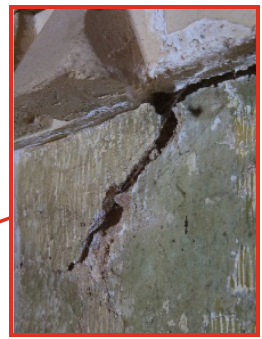

b

Fig. 4. Cracks in the 19th-century cornice and ceiling in the southwest corner of Margaret of Bavaria's dressing-room (a) and a detail showing a plaster filling detachment (b), (C) Germolles.

To this end, they requested the technical support of the Institute for Spatial Information and Surveying Technology of the University of Applied Sciences (i3mainz) in Mainz, Germany.

\section{Imaging Techniques Used}

Since the 19th century cornice is believed to play a key role in the observed physical damage, we decided to document and monitor its network of microcracks over time. Because of the geometric accuracy and micro-resolution required, only high-resolution structured light techniques, embedded in a frame of close-range photogrammetry, are able to provide the necessary quality. Although these techniques are well known and well tested [4-6], their application has been made difficult by the position of the object about $4 \mathrm{~m}$ above the ground and the limited possibilities to use installations on or around the object. The analysis of changes over time therefore also had to be done in a relative manner. 


\subsection{Preparation of the Cornice}

Fortunately, a few targets could be placed over the entire surface of the cornice providing a minimum of geometric information for data acquisition. As these have to be discreet and removed non-invasively, circular uncoded black and white targets of $1 \mathrm{~cm}$ diameter were used, glued with Paraloid B72 diluted in acetone. In order to prevent the latter from irreparably marking the plaster of the cornice when the targets are removed, a layer of cyclododecane, which sublimates in the atmosphere, was previously applied between the plaster and the adhesive. The targets are not referenced in a superordinate system (Fig. 5a).

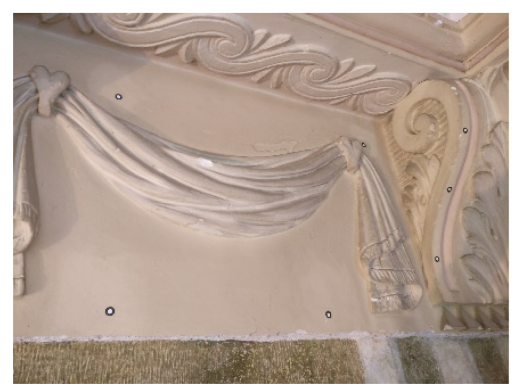

a

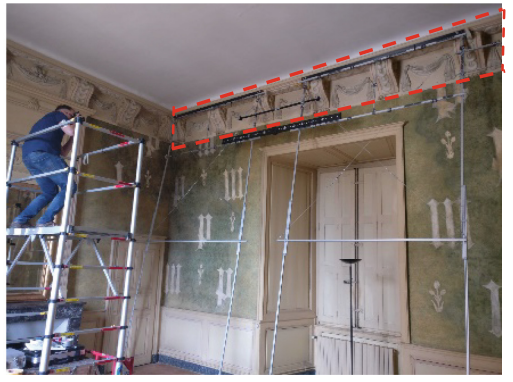

b

Fig. 5. Target distribution on a cornice segment of Margaret of Bavaria's dressing-room (a) and photogrammetric campaign on the south wall (triangulated area in red) (b), (C) Germolles. (Colour figure online)

\subsection{Workflow of the Photogrammetric and Scanning Campaigns}

In order to obtain the actual geometry of the targets, we applied a photogrammetric triangulation prior to each campaign. Due to the location of the cornice, we established a temporary point field allowing to connect the images and to position scale bars. During the different campaigns, it was visible that the movement of the scaffolding used by the operator (Fig. 5b) induced vibrations resulting in movements of the temporary points. The points frame was therefore reinforced in order to improve the stability of the network. As camera, we used a Nikon D800 with a $35 \mathrm{~mm}$ lens that was pre-calibrated on-site.

We used GOM TRITOP Professional 2016 as a tool for triangulation and achieved an average rms quality of 0.1 pixel in the images, $0.033 \mathrm{~mm}$ at the object points and $0.05 \mathrm{~mm}$ at the scale bars. This gave us the basis for the geometrical analyses of the object in the requested order of a tenth of millimetre. The target points give the frame for the following scanning process performed with a GOM ATOS Core 500, providing individual scans with a resolution of $0.19 \mathrm{~mm}$ and a coverage of $360 * 380 \mathrm{~mm}^{2}$ per scan. This resulted in 20 scans per segment. During the scanning process, the scanner 
was mounted on a tripod, which was securely attached to the scaffolding platform (Fig. 6). This non-standard build-up resulted in an increased vulnerability to scanner movements during the measurement. Although the scanning software checks the data in order to detect measurement inaccuracies due to scanner movements, some perturbations were created in the 3D mesh which were eliminated through post processing. GOM ATOS Professional 2016 software was used for data acquisition and processing.

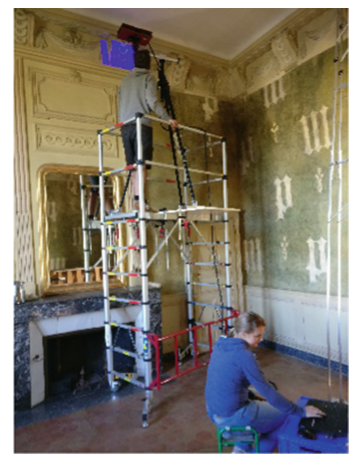

Fig. 6. Scanning campaign with the scanner GOM ATOS Core on the east wall, (c) Germolles. (Colour figure online)

Four measurement campaigns were carried out: two in late spring (campaigns 1 and 3 in May-June 2018 and 2019), a few weeks after the château's heating system was shut down, and two in autumn (campaigns 2 and 4 in late September-early October 2018 and 2019), just before the heating system was restarted. Each campaign provided individual 3D models of the cornice for each of the walls together with the corresponding field of target points.

\section{Results}

\subsection{Deformation of the Cornice Over Time}

Both data sets (3D models, 3D target points) allow us to analyse changes of the geometry over time. In this context, two questions need to be addressed: (1) does an individual wall show a deformation over time, and (2) are there microscopic changes (such as cracks) that can be identified and express possible local deterioration? Since we do not have an absolute reference serving as base for an analysis, we compared all individual data sets by means of geometric transformations. In the case of the targets points we could apply regular coordinate transformations, while for the $3 \mathrm{D}$ models we applied best fit transformations which are part of the GOM software package. One 
example for transformation results is shown in Fig. 7, comparing the 3D models of the summer and early autumn campaign (west wall). It shows clear global changes where the centre of the wall behaves opposite to the corners.

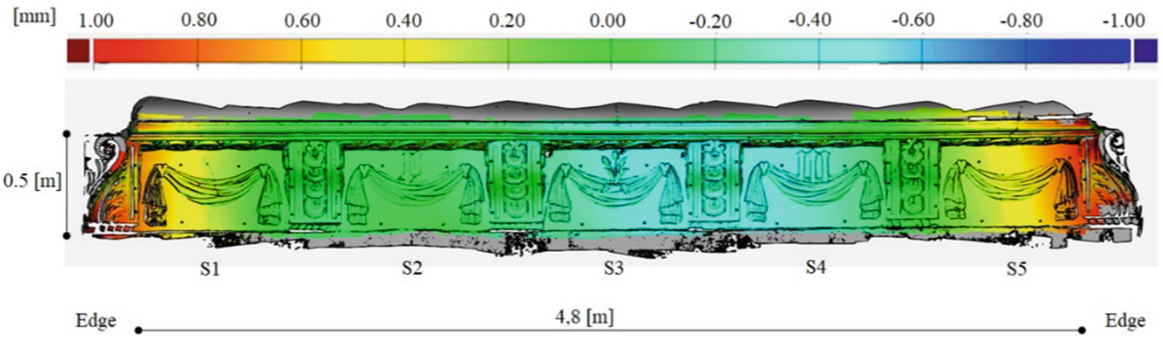

Fig. 7. Result of best fit transformation for two 3D models of the cornice of the west wall (campaigns $1 \& 2$ ), (C) i3Mainz. (Colour figure online)

Further studies of these global changes use the field of target points transformed by means of a least square 6 parameter transformation. Figures $8 \mathrm{a} \& 8 \mathrm{~b}$ compare the results of campaigns $1 \& 2$ and $2 \& 3$. As in Fig. 7, we identify global changes from spring to autumn 2018 ( $1 \& 2$ ) and also from autumn 2018 to spring 2019 (2 \& 3). As local trends are similar but in opposite directions, it appears that cornice movements are documented as small oscillations (less than $0.5 \mathrm{~mm}$ ) where areas move back and forth.

Similar phenomena were observed on the south wall between the 1st and 3rd campaigns, although more pronounced and to a much lesser extent between the 3rd and 4th campaigns. The north wall and the east inner wall were each measured in two parts. It is therefore not possible to comment on the movement of the whole wall as for the other walls. The cornice moved much less in both parts of the east wall. The smallest movement was observed in the parts of the north wall.

\subsection{Visualization of Micro-deformations}

Global deformations of the walls make it difficult to analyse deformations on the millimetre scale (at the level of the cracks). In order to answer the second question (are there local deformations), we analysed the individual wall segments (S1-S5 on Fig. 7 for west wall) separately. For this purpose, we applied a best fit transformation between two entire 3D models of an individual segment and visualized the results. As a visualization tool, we used 3DHOP and added functionality to display all difference models (from $1 \& 2,1 \& 3, \ldots$ up to $3 \& 4$ ).

Figure 9 gives examples for the west wall (left side: S1, right side: S4). Figures 9a and $9 \mathrm{c}$ show that between scan campaigns 2 and 3 , segment 1 of the cornice of the west wall of Margaret of Bavaria's dressing-room moved little, except in the area indicated by a red circle. In this wide crack, it appears that one of the fragments moved from the 


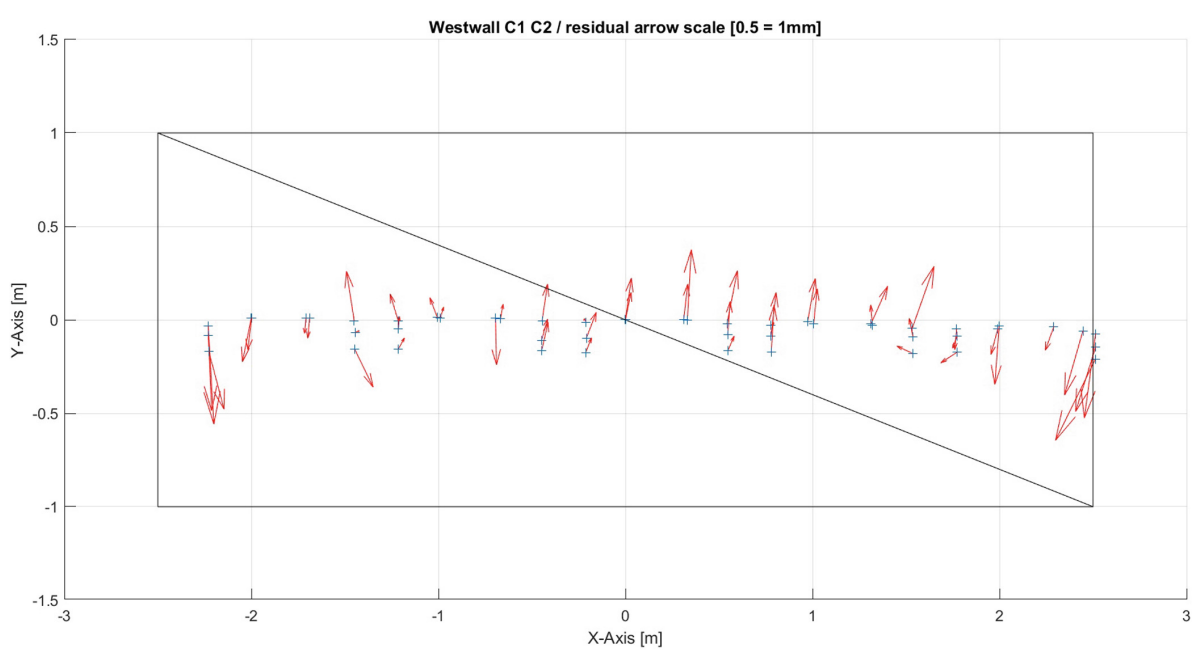

a

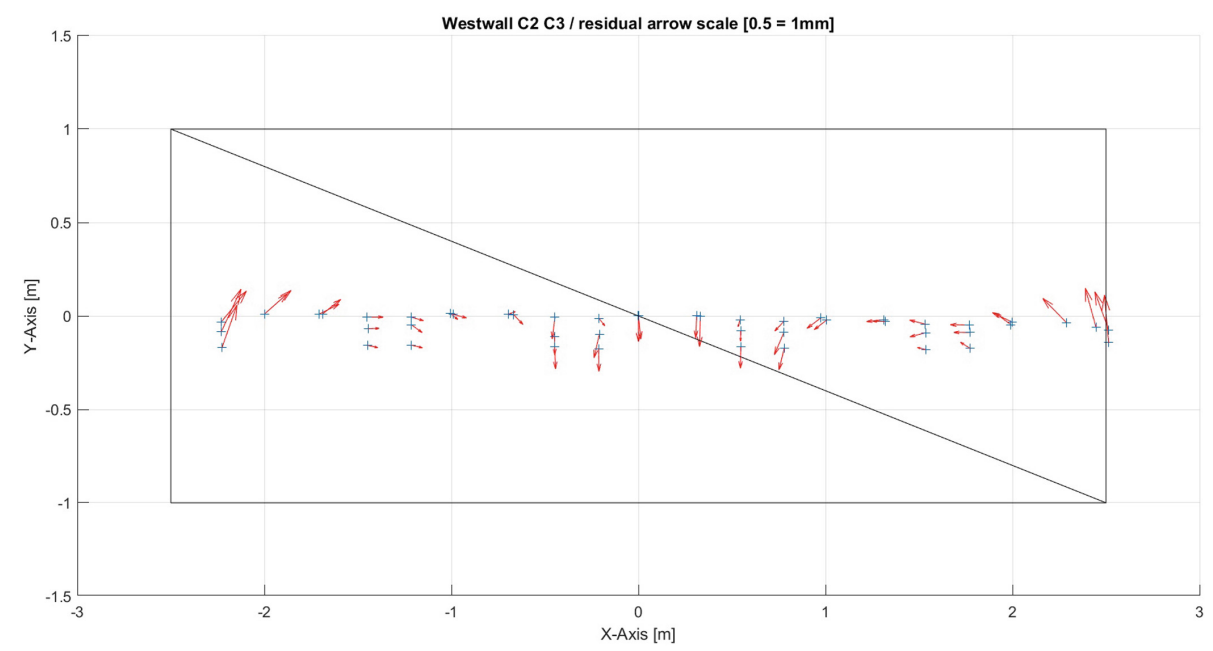

$\mathrm{b}$

Fig. 8. Visualization of the relative displacement of the targets of the cornice of the west wall of Margaret of Bavaria's dressing-room between the 1st and 2nd (a) and between the 2nd and 3rd campaigns (b), C i3Mainz. (Colour figure online)

inside to the outside. This movement is confirmed between scan campaigns 3 and 4 (Fig. 9e) but to a lesser extent and extends to the lower part of the cornice segment. Colour/uncoloured edges of the difference model (red arrows Fig. 9e) result from difficulties to access the area directly below the ceiling, resulting in less overlap of the scans. These side-effects are not documenting physical movements. A larger object movement is observed on the side of one of the volutes between campaigns 3 and 4 (Fig. 9f). 


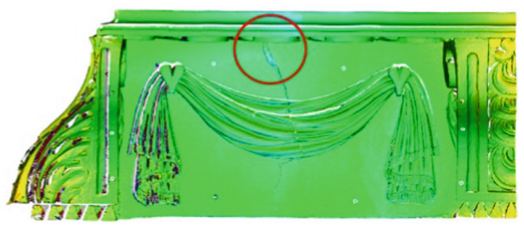

a

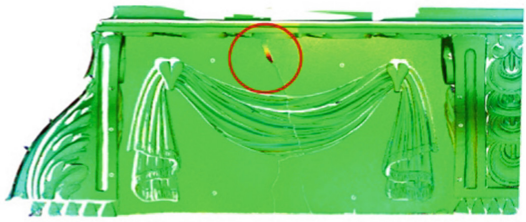

C

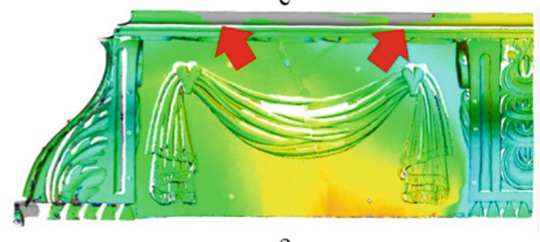

e

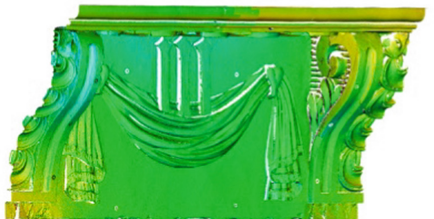

b

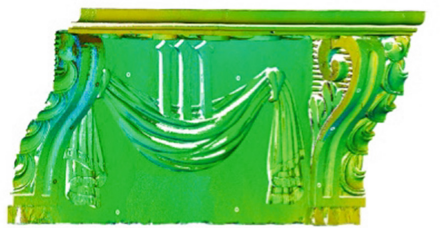

d

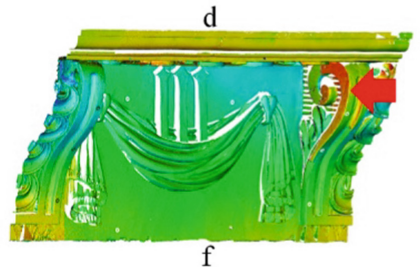

f [mm]

Fig. 9. 3D models of segments 1 and 4 of the cornice of the west wall of Margaret of Bavaria's dressing-room and comparison between scans 1/2 (a), 2/3 (c) and 3/4 (e) for segment 1 and 1/2 (b), $1 / 3$ (d) and 1/4 (f) for segment 4, C i3Mainz. (Colour figure online)

These few damages are the only ones that could be clearly observed on the four walls during the four campaigns.

\subsection{Discussion}

It should be noted that in the absence of an absolute reference, we only analysed the relative deformations of the different elements or segments of the $19^{\text {th }}$ century cornice. This choice of approach is linked to the prestigious nature of the mural paintings, which did not allow targets to be fixed on them.

The movements of the cornice seem more related to its position on a wall exposed to more or less sun and western rain than to the change of seasons. This is the case for the south and west walls and appears to be reflected in an outward expansion movement of the cornice during the summer and early autumn of 2018, while it appears to have contracted from late autumn 2018 to spring 2019. This phenomenon seems to be repeated for the west wall, but to a lesser extent, the following year. It is less acute in the second year for the south wall.

The cornice of the north wall, which is only sunny at the end of the day in summer and receives some rain, is much less affected. The fact that it is interrupted in its central part by a window may also play a role. The cornice of the inner east wall seems to be subject to some movement in the southeast corner. 
These expansion and contraction movements remain minimal (max. $0.5 \mathrm{~mm}$ ) but cause local damage of some cornice segments, especially those that are already partially detached or near major cracks. It is interesting to note that the cornice of the west wall seems to be the most affected as shown in Fig. 9 but also with its important network of cracks. The cornice of the south wall, which is under great stresses, is less affected. Its movements, however, have an impact on the adjacent cornice elements, that of the west wall as seen above, but also that of the east wall less stressed but very much affected as shown again by the extensive network of cracks.

\section{Conclusion}

This work shows results of the application of photogrammetry and structured light techniques allowing to document the geometry of the cornice of Margaret of Bavaria's dressing-room at Château de Germolles over a period of two years. Although the constraints given by the object as such (size, extend, position under the ceiling) and the required accuracy (tenth of a millimetre) made the task difficult, it was possible to obtain the required quality for the analysis. It revealed cornice movements, as expected, due to seasonal temperature and humidity changes. However, the reversibility of the deformations dispels our fears of major damage.

Acknowledgments. This project would not have been possible without the financial support by Regional Direction of Cultural Affairs of Burgundy - Franche-Comté which the authors wish to sincerely thank.

\section{References}

1. Degrigny, C., Piqué, F., et al.: Wall paintings in the château de Germolles: an interdisciplinary project for the rediscovery of a unique fourteenth century decoration. In: Bentkowska-Kafel, A., MacDonald, L. (eds.) Digital Techniques for Documenting and Preserving Cultural Heritage, pp. 67-86. Arc Humanities Press, Kalamazoo (2017)

2. Beck, P.: Vie de cour en Bourgogne à la fin du Moyen Âge. Alan Sutton, Saint-Cyr-sur-Loire (2002)

3. ADCO B 4434-1. Archives départementales de Côte d'Or: Baillage de Dijon, compte ordinaire - 1389-1390. f. $22 \mathrm{v}^{\circ}-24$

4. Hanke, K., Böhler, W.: Recording and visualizing the cenotaph of German Emperor Maximilian I. Int. Arch. Photogram. Remote Sens. 35(5), 413-418 (2004)

5. Wiemann, A.-K., Boochs, F., Karmacharya, A., Wefers, S.: Characterisation of spatial techniques for optimised use in cultural heritage documentation. In: Ioannides, M., MagnenatThalmann, N., Fink, E., Žarnić, R., Yen, A.-Y., Quak, E. (eds.) EuroMed 2014. LNCS, vol. 8740, pp. 374-386. Springer, Cham (2014). https://doi.org/10.1007/978-3-319-13695-0_36

6. Luhmann, Th.: Nahbereichsphotogrammetrie, Grundlagen - Methoden - Beispiele. Wichmann, Berlin (2018). ISBN 978-3-87907-640-6 